\title{
Hoe dink vandag se mense oor die Bybel? ${ }^{1}$
}

\section{J J Spangenberg}

(Universiteit van Suid-Afrika)

\section{ABSTRACT}

\section{How do people from our day and age view the Bible?}

Not all members of the Dutch Reformed Church cherish the same view about Scripture. The letters in the Afrikaans newspapers on religious issues clearly reflect this. There are two groups of scholars in the church whose views on Scripture impact on church members' views. They are (1) systematic theologians and (2) biblical scholars. A large number of systematic theologians adhere to the view which was formulated during the heydays of Protestant Orthodoxy, i.e. that the Bible reflects a double authorship. They prefer to use the Latin words "auctor primaries" and "auctores secundarii" when writing about Scripture. A large number of biblical scholars, however, work with the idea that the Bible reflects single authorship. God did not write. Humans wrote the books of the Bible. It goes without saying that ordinary church members do not always understand the differences and are often perplexed by these differences. It is of utmost importance to discuss these differences and to try and find some middle ground in the church.

\section{INLEIDING}

The most widely read book in the world is not necessarily the bestread book. There are two sorts of reading. There is the sort we learned long ago, when we were five or six. The other sort is reading with understanding, receiving the text on the right wavelength (Fokkelman 1999:7).

Daar is twee groepe binne die Ned Geref Kerk wie se sienings oor die Bybel 'n impak het op gewone lidmate se sienings van die Bybel. Hulle is (1) dogmatici/sistematiese teoloë, en (2) Bybelwetenskaplikes. Dis nie twee groot groepe binne die kerk nie, maar beide groepe het 'n duidelike invloed op hoe predikante en lidmate die Bybel sien en lees. Hierdie

1 Die Instituut vir Erediensnavorsing en -Toerusting van die Universiteit van Pretoria en die Bediening vir Aanbidding van die NG Kerk Oos-Transvaal het op Maandag 4 Maart 2002 'n konferensie aangebied met die tema "Kan ons die Bybel dan nog preek?" Hierdie artikel is gebaseer op "n lesing wat ek by die konferensie voorgedra het. 
twee groepe dink nie presies dieselfde oor die Bybel nie. Hierdie saak het die afgelope paar jaar al duideliker geword. Daar is weliswaar enkele Bybelwetenskaplikes wat baie nou aansluit by dogmatici se siening van die Bybel. Maar daar is ' $n$ beduidende aantal Bybelwetenskaplikes wat hulleself nie tuis voel binne die sienings van dogmatici nie. Hulle voortdurende lees van die Bybelteks, en hulle bestudering van die politieke en godsdienstige geskiedenis van Israel en die Jode, het hulle siening van die Bybel verander. In alle billikheid moet 'n mens wel erken dat daar enkele dogmatici is wie se Skrifbeskouing nouer aansluit by die tweede groep (Bybelwetenskaplikes) as by hulle eie vakgenote. Hierdie dogmatici is egter in die minderheid.

\section{DIE WYSE WAAROP DOGMATICI OOR DIE BYBEL DINK: DUBBELE OUTEURSKAP}

Die wyse waarop dogmatici en predikante binne die Ned Geref Kerk oor die Bybel dink, word nêrens elders so duidelik geïllustreer nie as in die boek van Heyns Brug tussen God en mens: Oor die Bybel (1973) en die boek van Potgieter Skrif, dogma en verkondiging (1990). 'n Mens kan hierdie siening soos volg saamvat: Die Bybel het 'n dubbele outeurskap. God is die eerste of primêre skrywer en mense is die ondergeskikte of sekondêre skrywers. Ons kan dit soos volg deur middel van die kommunikasiemodel weergee:

Auctor Primarius ? Menslike skrywers ? $\quad$ Teks ? $\quad$ Lesers

\subsection{Enkele voorbeelde}

Wanneer die bovermelde dogmatici oor die Bybel skryf, duik die Latynse woorde auctor primarius en auctores secundarii dikwels op. Oor hierdie dubbele outeurskap skryf Heyns die volgende: "Ook by Rome word die dubbele outeurskap van die Skrif gehandhaaf en wel so dat die mens aan God ondergeskik is" (1973:31, voetnoot 11). Alhoewel Heyns baie maak van wat hy "die dialogiese karakter van die Bybel" noem, ken hy nie aan die skrywers 'n eie selfstandige inset toe nie: "Dat die Bybelskrywers op Gods woord geantwoord het, wil vir geen oomblik sê dat hulle eers daaroor besin en daarop kommentaar gelewer het en dit tóe op Skrif gestel het nie" (1973:42).

Byna dieselfde gedagtes vind ons ook by Potgieter wanneer hy skryf: "Daar moet meteens op 'n groot gevaar gewys word, naamlik dat die menslike karakter van die Heilige Skrif so sterk benadruk kan word dat sy Goddelike gesag daardeur in die gedrang kom". En dan vra hy in 
'n volgende paragraaf die volgende: "As daar gepraat word van die een of ander Skrifuitspraak van Paulus of van Matteus of van Lukas, ontstaan die vraag of daar dan ook sonder meer gesê kan word dat dit tegelyk werklik en in eintlike sin die Woord van God is" (Potgieter 1990:23).

Hierdie siening is ook gedeeltelik te vind in die beleidsdokument van die Algemene Sinode van 1986: "As Auctor primarius het Hy daarvoor gesorg dat hulle met hulle skryfwerk presies weergegee het wat sy Goddelike bedoeling daarmee was". Dit kom ook voor in die boekie Die Bybel bly steeds God se Woord van J J Swart (2000) waarin hy Geloofsverklaring 2000 se bewoording oor hoe ons die Bybel moet verstaan, kritiseer. Geloofsverklaring 2000 het die saak so gestel: "Dat die onderskeie dele van die Bybel verskillend aangebied word - as vertellings oor die voorgeskiedenis, profesieë, gedigte, reisbeskrywings, verhale, briewe - en dat elke skrifdeel aan die hand van sy besondere aard en in die lig van die geheel verstaan en verklaar moet word". Swart (2000:41) sê hiervan: "Hier is die stem te hoor van 'n ernstige noodlottige moderne neiging wat die Bybel slegs as gewone menslike letterkunde wil beskou, 'Menslike woorde oor God' soos beweer word. Weereens die miskenning dat God die Primêre Outeur van die Bybel is" (klem bygevoeg).

Hierdie soort "waarskuwing" weerklink ook in 'n artikel van Doubell en Strauss (2001:309):

Die bedoeling van die auctor primarius kom hoegenaamd nie ter sprake nie, omdat die Skrif in sekere kringe nie meer as Woord van God gesien word nie. As die bedoeling van die auctor primarius wel verreken wil (sic) word, is dit duidelik dat die oorspronklike konteks en die huidige konteks nie die enigste norm vir die verstaan van die Skrif kan wees nie. Die konteks is die wisselende faktor by die verstaan van die teks, maar daar is ook 'n vaste punt wat verreken moet word.

Daardie vaste punt is, volgens Doubell en Strauss, die bedoeling van die auctor primarius. Selfs die Nuwe-Testamentikus P J du Plessis het met die idee van dubbele outeurskap gewerk. Dit blyk duidelik uit die volgende sin: "In die geval van die Evangelie is die primêre outeur God en die direkte of sekondêre outeur een van die vier Evangeliste" (Du Plessis \& Lategan 1983:69).

\subsection{Waar kom hierdie siening vandaan?}

As ons teruggaan in die geskiedenis en ondersoek instel waar hierdie siening vandaan kom, sal sommige predikante stom van verbasing staan. Dit kom nie direk van die Hervorming nie, maar via die Protestantse Ortodoksie van die sewentiende en agtiende eeu! Dis dan ook geen won- 
der nie dat Koekemoer (1994:87-94) van die Ned Herv Kerk in Afrika, Heyns se beoefening van die dogmatiek beskryf as "dogmatiek in die rigting van die Gereformeerde Ortodoksie". Dis eers tydens die Protestantse Ortodoksie dat die leerstuk van die inspirasie van die Skrif na vore gekom het. Tydens daardie jare is die diktaat-teorie (die idee dat God die woorde vir die skrywers voorgesê het) ontwikkel. Ter motivering van die standpunt is na 2 Timoteus 3:16 verwys. Die gebruik om tekste uit verskillende Bybelboeke aaneen te ryg om 'n bepaalde dogma se Skriftuurlikheid en Goddelikheid te bewys, is kenmerkend van die Protestantse Ortodoksie. Die aanhalings verraai dikwels dat die aanhaler nie ag geslaan het op die soort literatuur, die stylfigure, en die historiese en literêre konteks nie. Alle Bybelwoorde is immers Goddelike woorde en kan daarom lukraak ingespan word om 'n saak te beredeneer. Selfs die Skrifgebruik van die Nederlandse Geloofsbelydenis vertoon trekke van die Protestantse Ortodoksie (vgl Bosman 1987:67; Scheffler 1987:86).

Gaan 'n mens terug na Calvyn, is dit opvallend dat hy in sy Institusie waar hy oor die Skrif skryf, geen inspirasieleer ontwikkel nie. Diegene wat reken dat Calvyn wel 'n diktaatteorie voorgestaan het, kan gerus gaan lees wat hy oor sekere skrywers van die Nuwe Testament skryf. Van Petrus sê hy dat hy (Petrus) 'n klomp sake op 'n uiters verwarrende wyse bymekaar gevoeg het. En by Romeine 3:4 merk hy op: "Ons weet wel dat die apostel dikwels taamlik vry aanhaal uit die Skrifte" (vgl Hartvelt 1968:17). Calvyn toon met hierdie stellings dus begrip vir die feit dat mense die Bybelboeke geskryf het; mense wat nie as sekondêre outeurs geklassifiseer kan word nie. Hulle was die primêre outeurs wat inligting versamel en dit geïnterpreteer het. Hulle het die literêre genres en die stylfigure gekies deur middel waarvan hulle hulle gedagtes uitgedruk het.

\subsection{Waartoe lei hierdie siening?}

Ammerman (1987:51) beskryf die gevolge van die dogmatiese siening van die Bybel kort en bondig: "[B]ecause God is the timeless author of every word and story, the Bible need not be interpreted in a historical and literary context". Met hierdie soort siening van die Bybel kom 'n dogmatikus, predikant en lidmaat maklik oor die weg. Jy hoef geen moeite te doen om die historiese en literêre konteks te verreken nie. Jy lees die Bybel asof dit van begin tot end een en dieselfde literatuursoort is. Jy lees die Bybel van voor- tot agterblad soos geskiedenis. Jy verreken vir geen oomblik die werklike historiese konteks waarin die literatuur tot stand gekom het nie. God spreek jou direk aan deur die teks.

'n Mens sou wel kon argumenteer dat Heyns en Potgieter meer genuanseerd oor die inspirasie skryf en dat hulle 'n groter waardering vir die menslike karakter van die Skrif het. Om egter waardering te hê vir 
"die menslike karakter" van die Skrif, beteken geensins dat jy waardering het vir die feit dat gewone mense dit geskryf het nie. Dit beteken ook nie dat jy daarmee erken dat gewone mense nagedink en hulle stof georden het toe hulle geskryf het nie. Die wyse waarop hierdie dogmatici hulle sienings verwoord, laat eintlik geen ruimte vir eie geloofsinsigte, eie formulerings en eie verwerking van die materiaal nie. Hulle is ook kopsku vir die idee dat daar ontwikkelings op die terrein van die Israelitiese godsdiens, die Judaïsme en die Christelike godsdiens was. Die godsdiens van Abraham is volgens hulle siening dieselfde as die godsdiens van Moses en Dawid en Paulus. Alles staan op een lyn. Die Israelitiese godsdiens het volgens hierdie siening dan ook met die geboorte van Jesus Christus sy eindpunt bereik. Die Christelike godsdiens het in die plek daarvan gekom. Die Judaïsme word daarom beskou as 'n afwykende stroming (of godsdiens) wat sy ontstaan het in Jode se hardnekkige weiering om Jesus as Messias te aanvaar. Daarom kan 'n sendingkundige wie se boek Wie het die waarheid beet? hierdie soort Skrifbeskouing verraai. Hy skryf die volgende oor die Judaïsme: "Die eerste groot godsdiens wat die vroeë kerk ontmoet het, was die Jodedom" (Verster 1997:13).

Let eerstens op na die verwarrende terminologie. Die woord "Jodedom" word vir sowel 'n groep mense as 'n godsdiens gebruik. Voorts klink dit asof die Christendom uit die niet in Palestina verskyn het. Hy verreken vir geen oomblik die feit dat die vroeë Christene - en Jesus - Jode was en ook die Joodse godsdiens van hulle dag beoefen het nie. Hierdie godsdiens staan vandag onder Bybelwetenskaplikes bekend as "vroeë Judaïsme". Dogmatici en predikante kleef nog aan die ou terminologie "Laat-Jodedom" vas (vgl König [2001:26, 68, 96] wat nog praat van "Laat-Joodse apokaliptiek").

Die ekstreme vorm van hierdie soort Skrifbeskouing maak 'n sinvolle gesprek oor enige godsdienstige onderwerp onmoontlik. Die volgende spreuk wat soms op motorbuffers te sien is, vat die saak goed saam: "God said it. I believe it. That settles it". Met so 'n soort Skrifbeskouing kan teologiese fakulteite maar sluit, want dit maak teologiebeoefening onmoontlik.

\section{DIE WYSE WAAROP BYBELWETENSKAPLIKES OOR DIE BYBEL DINK: ENKEL OUTEURSKAP}

As daar één Bybelwetenskaplike van die twintigste eeu uitgesonder moet word wat meer as ander oor die Bybel besin en geskryf het, is dit James Barr. Hy kon dinge duidelik analiseer en foutiewe redenasies presies uitwys. Boek na boek van Barr (vgl 1966; 1973; 1977; 1980; 1984) het 'n invloed uitgeoefen op Bybelwetenskaplikes dwarsoor die wêreld. Ook in Suid-Afrika was dit die geval. Sy insigte skemer duidelik deur in die 
publikasies van Deist (1982; 1986), Vorster (1977; 1979) en Spangenberg (1998). In 'n enkele sin kom dit daarop neer dat die Bybelboeke nie 'n dubbele outeurskap het nie, maar slegs 'n enkel outeurskap. Mense het Bybelboeke geskryf en dis menslike insigte waarmee ons te doen kry wanneer ons die Bybel lees. Barr (1973:120) stel dit soos volg: "If one wants to use the Word-of-God type of language, the proper term for the Bible would be Word of Israel, Word of some leading early Christians". Ons kan dit soos volg deur middel van die kommunikasiemodel weergee. Ek gebruik die Johannesevangelie as illustrasiemateriaal:

\begin{tabular}{|ccc|}
\hline Skrywer & $? \quad$ Teks & Lesers \\
Johannes & Vierde evangelie & Christene in Efese \\
\hline
\end{tabular}

Dogmatici, predikante en lidmate wat voorstanders is van dubbele outeurskap, reageer gewoonlik op hierdie uiteensetting deur die stelling te maak dat 'n mens met so 'n standpunt die Bybel btaal devalueer. As die Bybelboeke slegs maar deur mense geskryf is, het dit geen gesag meer nie (vgl Janse van Rensburg 2000:61).

Bybelwetenskaplikes wat Barr se siening aanvaar, wys egter daarop dat hulle steeds met die werking van die Gees rekening hou (vgl Deist 1986:67-78; Spangenberg 1998:107-118), want, alhoewel dit 'n feit is dat die Bybelboeke deur mense geskryf is, is dit ook 'n feit dat dit gelowige mense was wat geskryf het, mense wat met God in 'n verhouding gestaan het. Ons kan dit op die volgende wyse, deur middel van 'n uitbouing van bostaande diagram, weergee:

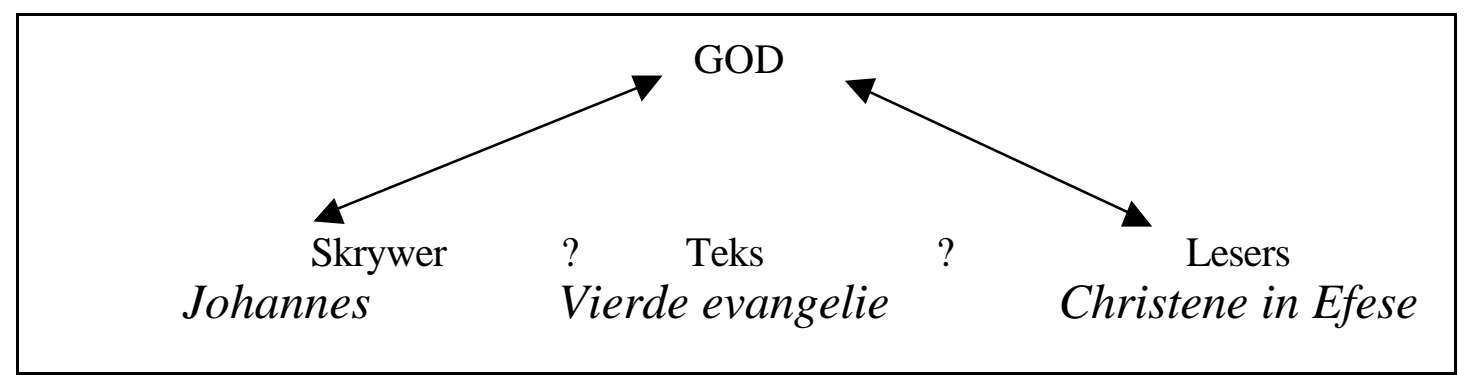

Met die Johannesevangelie as voorbeeld, is dit duidelik dat die skrywer met God in 'n verhouding gestaan het. God het ook sekerlik met sy Gees op hierdie skrywer ingewerk. Hierdie onbekende skrywer (hy is nie die dissipel Johannes nie) skryf sy evangelie vir Christene wat aan die begin van die tweede eeu n.C. in Klein-Asië (moontlik Efese) geleef het (vgl Schnelle 1998:475-477). Ook húlle het met God in 'n verhouding gestaan en die werking van sy Gees geken. 
Wanneer ons hierdie evangelie noukeurig lees, en dit vergelyk met gegewens in die ander drie evangelies, is daar opvallende verskille. Vergelyk slegs die volgende voorbeelde:

- Die reiniging van die tempel (Joh 2:14-22) staan aan die begin van die evangelie en nie aan die einde, soos by Matteus, Markus en Lukas nie.

- In Johannes onderneem Jesus ten minste drie keer 'n reis na Jerusalem (Joh 2:13, 5:1, 7:10), terwyl Hy slegs een maal en dan ook teen die einde van sy lewe na Jerusalem reis volgens Matteus, Markus en Lukas.

- In Matteus, Markus en Lukas speel die koninkryk van God 'n oorheersende rol. In die Johannesevangelie kom die uitdrukking "koninkryk van God" slegs maar in Johannes 3:3 en 3:5 voor.

Hierdie verskille hou waarskynlik daarmee verband dat die skrywer nie 'n ooggetuie van die gebeure rondom Jesus se lewe was nie. "He was a theologian of the later period who, on the basis of comprehensive traditions, rethought the meaning of Jesus' life, and interpreted and presented it in his own way" (Schnelle 1998:474). Hierdie stelling sal sommige dogmatici en predikante in die Ned Geref Kerk koue rillings gee, maar Bybelwetenskaplikes kan op geen ander manier die verskille tussen die evangelies sinvol aan mense verduidelik nie. Buitendien, as God die eintlike skrywer van al vier die evangelies is, waarom deel Hy sulke verwarrende inligting aan ons mee?

\subsection{Waar kom hierdie siening vandaan?}

Alhoewel ek Barr as die doyen van hierdie siening getipeer het, is dit nie so dat hierdie beskouing nie "ou papiere" het nie. Hierdie beskouing is inderwaarheid terug te vind by sommige van die hervormers van die sestiende eeu. Steve Moyise (1998:10) het die volgende diagram ontwerp om die verandering wat die Hervorming meegebring het, te illustreer. Daar is 'n vertikale lyn (kerk - teks - lidmate) en 'n horisontale lyn (skrywer - teks - lesers). Die vertikale lyn weerspieël die kerklike beheer oor die Bybel gedurende die Middeleeue (500-1500). Die horisontale lyn weerspieël die besef wat by sommige hervormers bestaan het dat die Bybelboeke kommunikasie tussen skrywers en lesers was.

Tydens die Middeleeue het die kerkleiers "beheer" oor die Bybel gehad. Kerkleiers het die teks vir lidmate gelees en geïnterpreteer. Lidmate kon nie die teks self lees en kontroleer of dit wat aan hulle verkondig is die waarheid is nie. Die Bybel was op daardie stadium in Latyn vertaal. Beter gestel: Latyn was die kerktaal, en hierdie taal was grootliks ontoeganklik vir gewone lidmate. Die Hervorming het 'n radikale 
verandering gebring toe die Bybel in die spreektaal van lidmate vertaal is en die menslike karakter van hierdie boeke aan die lig gebring is.

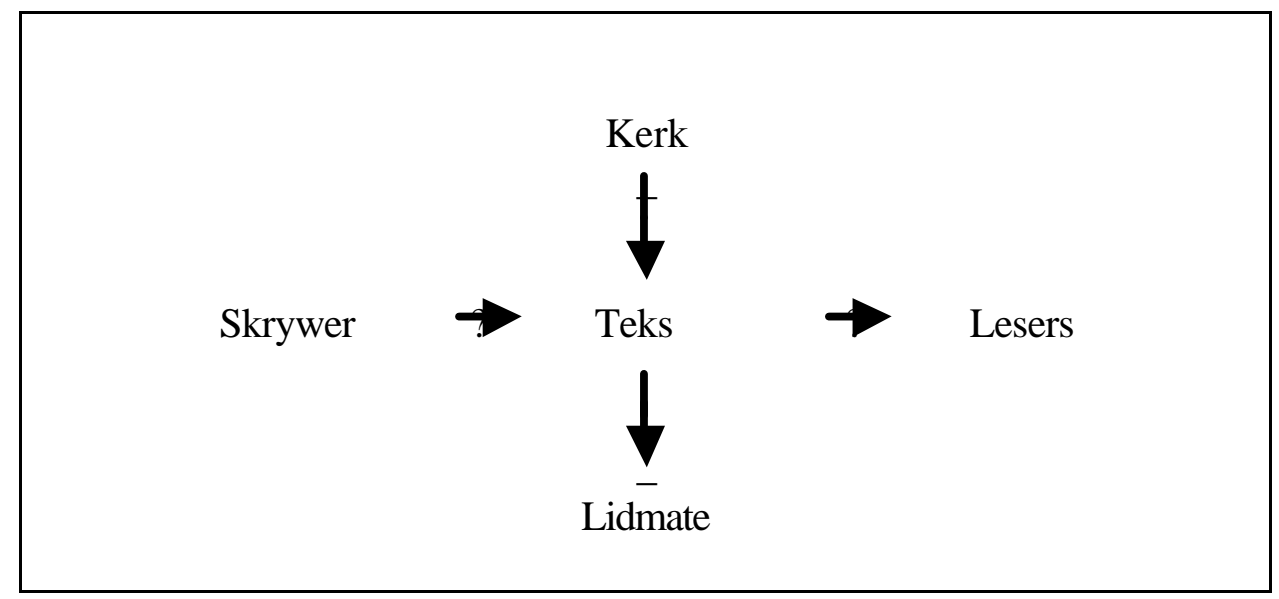

Alhoewel dit aan 'n anakronisme grens om te beweer dat die Hervormers reeds ten volle daarvan bewus was dat Bybelboeke gewone kommunikasie tussen skrywers en lesers was, lê daardie siening tog ingebed in hulle skrywes. Die bybelwetenskaplike paradigmaverandering aan die einde van die negentiende eeu het hierdie oortuiging egter finaal deel laat word van Ou- en Nuwe-Testamentici se denkraamwerk. Bybelwetenskaplikes het ernstige navorsing begin doen oor die leefwêreld van die mense van destyds en heelwat argeologiese ontdekkings is gedurende die negentiende eeu in die Midde-Ooste gemaak.

Daar bestaan 'n magdom literatuur oor die geskiedenis van Bybelinterpretasie sedert die Hervorming. Skrywers is dit eens dat die studie van die Bybel in die negentiende eeu 'n radikale omwenteling ondergaan het. Daar het soveel nuwe feite oor die wêreld van die Bybel en die oorsprong van die Bybelboeke in daardie jare na vore gekom dat dit tot 'n paradigmaverandering gelei het (vgl Spangenberg 1994:145-156; 1998: 10-24). Hierdie paradigmaverandering kan ' $\mathrm{n}$ mens in kort die historieskritiese paradigma doop. Van die histories-kritiese Bybelondersoek sê Den Heyer (1988:134) die volgende: "Het historisch-kritisch onderzoek laat geen andere conclusie toe: de bijbel is een 'tijdgebonden' boek en de schrijvers waren gewone mensen". Oosterhoff (1968:50) beklemtoon weer dat die navorsing tydens die negentiende eeu uitgewys het dat die Ou Testament 'n Oosterse boek is wat binne dáárdie kultuur verstaan moet word: "Meer dan vroeger is duidelijk geworden dat de Schrift een oosterse boek is en met name het Oude Testament met duizenden banden verbonden is aan de oud-oosterse cultuur- en denkwereld". Ons durf dit nie lees asof dit 'n boek is wat in die Westerse kultuur tot stand gekom het nie, anders misken ons die eie karakter daarvan.

Gedurende die twintigste eeu het daar egter 'n verdere paradigmaverskuiwing op die terrein van die Bybelwetenskappe voorgekom (vgl 
Spangenberg 1994:156-162; 1998:24-28). Die moderne literatuurwetenskap het 'n invloed op die studie van die Bybel begin uitoefen. Fokkelman (1999:206), wat heelwat navorsing oor die vertelliteratuur in Samuel en Konings gedoen het, gaan selfs so ver as om die volgende te sê: "Being able to work with such simple, but basic narratological tools as plot, hero and points of view is much more important in the encounter with the Bible than being devout". En Carroll (1991:101) skryf die volgende:

"The world of the text approach to reading the Bible is one of the best ways of reading such a literary production as the Bible. It resolves the insoluble problem of trying to relate the text to history, especially to the historical characters represented in the text. For example, the biblical Nebuchadrezzar is very different from what is known about the historical Babylonian emperor...."

\subsection{Sien ons oog om oog?}

Wanneer 'n mens die voorafgaande in aanmerking neem, sal mense kan verstaan waarom sommige dogmatici en Bybelwetenskaplikes in die Ned Geref Kerk nie oog om oog sien nie. Met die uitsondering van Van Huyssteen (1987) het geen ander dogmatikus al erns gemaak met die paradigmaveranderings wat ek hierbo beskryf het nie. En dit veroorsaak kortsluitings in die kommunikasie tussen Bybelwetenskaplikes en dogmatici (vgl Spangenberg 1994). Lidmate word ook hierdeur verwar, want hulle het nie die kennisraamwerk om die verskille te verstaan nie. As ek egter één dogmatikus mag uitsonder wat meer as ander 'n aanvoeling het vir die feit dat die Bybelboeke deur mense geskryf is, is dit Jonker. In een van sy voordragte wat hy tydens 'n CSV-kamp op Bainskloof gehou het, het hy die volgende gesê (Jonker 1975:6):

"Dit beteken dat ons die Bybel baie noukeurig moet lees en voortdurend vra na die bedoeling van die skrywer, amdat ons alleen só die bedoeling van die Gees kan leer ken. Om dit te kan doen, moet ek, soos by enige ander geskrewe stuk wat ek lees, altyd in gedagte hou dat die betrokke woorde in 'n bepaalde verband voorkom, dat hulle onder bepaalde omstandighede geskryf is, dat hulle in ' $n$ bepaalde stylvorm geskryf is, dat hulle in eerste instansie aan ' $n$ bepaalde adres gerig was en iets spesifieks aan daardie eerste lesers wou oordra".

Bybelwetenskaplikes kan na my mening hulle vind binne hierdie soort beskrywing van omgang met die Bybelboeke. Dit verreken sowel 
die historiese konteks waarbinne die literatuur tot stand gekom het as die soort literatuur wat die Bybelwetenskaplike lees en bestudeer. Om dan te kenne te gee dat ons só die "bedoeling van die Gees" kan begryp, lyk my nie haalbaar nie. Ons kan hoogstens sê dat dit is hoe dáárdie mense gereageer het op God se openbaring, of dan sy ontmoeting met hulle. Die openbaring lê daarom ook nie in die Bybel vasgevang nie, maar agter die Bybel in die gebeure wat onherhaalbaar verby is. In die woorde van John Barton (1988:56): "The Bible is people's reflection on their relationship with the known God: the knowledge, or revelation if you like, lies behind it rather than in it". Om dit na aanleiding van Jesus te formuleer. Ons bely tog dat God Hom in Jesus geopenbaar het. Daardie openbaring is onherhaalbaar iets van die verlede. Ons besit slegs getuienisse in die Nuwe Testament van mense wat iets daarvan beleef en daaroor nagedink het. Sommige, soos die skrywer van die Johannesevangelie, het dit nie eens beleef nie, maar hy skryf 'n boek om mense se denke oor Jesus te beïnvloed en mense hoop te gee. Ord en Coote (1994:51) som hierdie toedrag só op: "The intent of the gospels is not to chronicle the events of Jesus' life but to address issues of importance to the community of which the writer was a member".

\section{WAT VAN DIE GESAG VAN DIE SKRIF?}

Op die voorafgaande argumentering sou sommige mense sekerlik kon reageer en sê dat Bybelwetenskaplikes daarmee finaal die gesag van die Bybel prysgegee het. Die Bybel is nou maar net 'n menslike boek soos enige ander boek. Daar is geen rede waarom 'n mens dit nog enigsins moet lees en jou daaraan moet steur nie.

Wie egter só op Bybelwetenskaplikes se navorsing reageer, het nog nie mooi na hulle geluister en hulle publikasies gelees nie. Daar is weinig (indien enige) Bybelwetenskaplikes in die Ned Geref Kerk wat die Bybel by die agterdeur wil uitgooi, of wat die Bybel nie as gesagvol vir hulle geloof en lewe beskou nie. Diegene wat 'n ernstige studie van die Bybel maak, en kerklik betrokke is, wil graag hierdie nuwe inligting aan mense deurgee en hulle ook leer hoe om sinvol met die nuwe inligting om te gaan. Die oogmerk van Bybelwetenskaplikes is nie om mense se geloof te ondermyn nie, maar om mense by te staan in die herformulering van hulle geloof. Hierop sou mense kon reageer met die vraag: "Maar moet ons ons geloof dan herformuleer? Dis dan klaar in kruike en kanne!" Iemand wat só reageer, besef nie dat gelowiges wél hulle geloof moet deurdink en elke dag in die lig van nuwe inligting wat beskikbaar word, opnuut daaroor moet nadink nie. Daar is een sin in die boek van Harold Kushner (1982:141) wat my altyd sal bybly: "Isn't our own faith more securely ours because we worked it out from the material parents and teachers gave us, rather than because we inherited it intact?" 
Sommige mense beleef groot traumas (soos Harold Kushner) wat hulle geloof tot in sy wortels skud. Dit vra van hulle 'n grondige herbesinning oor hulle geloof. Ander loop weer inligting raak, wat hulle laat besef dat hulle nie meer kan glo soos hulle voorheen geglo het nie. Sulke mense is nie ongelowiges nie, maar is dikwels worstelaars wat poog om met intellektuele integriteit gelowig te bly.

As ek vir oulaas ' $\mathrm{n}$ geleerde mag aanhaal wie se wyse woorde vir my iets beteken, dan is dit die stelling van James Charlesworth, 'n kenner van die Dooie Seerolle. Dit kom voor in 'n opstel oor die Dooie Seerolle en die Christelike geloof (Charlesworth 1998:64-65):

"Dogmatics has been important in Christian history to clarify and defend the faith. That should be acknowledged, but it does not mean that what was defined as Christian faith for St. Augustine must be operative and constricting for us today. I am convinced that Augustine would have been opposed to such a move. It is now clear that we have insights into Jesus' time which Augustine did not know about, and that this new information, as well as the cultural climate at the end of the second millennium, necessitates finding new ways of expressing our understanding of Christian faith. Augustine struggled to shape faith - rather, the art of believing - for his time. Do we not have the same responsibility?"

Bybelwetenskaplikes ag die Bybel gesagvol omdat dit die basisdokument van die Christelike geloof is. Voorts sien hulle daardie gesag nie soos dié van 'n despoot nie, maar soos dié van 'n vriend op wie se insigte hulle kan vertrou (vgl Barton 1988: 45).

\section{Literatuurverwysings}

Ammerman, N T 1987. Bible Believers: Fundamentalists in the Modern World. New Brunswick: Rutgers University Press.

Barr, J 1966. Old and New in Interpretation: A study of the two testaments. London: SCM.

-, 1973. The Bible in the Modern World. London: SCM.

-, 1977. Fundamentalism. London: SCM.

-, 1980. The scope and authority of the Bible. London: SCM. (Explorations in Theology 7).

-, 1984. Escaping from Fundamentalism. London: SCM.

Barton, J 1988. People of the Book? The Authority of the Bible in Christianity. London: SPCK.

Berkouwer, G C \& Van der Woude A S (red) 1968. De Bijbel in het geding. Nijkerk: Callenbach.

Bosman, H L 1987. Die gebruik van die Ou Testament in die Nederlandse Geloofsbelydenis. In: Bosman, H L et al 1987:53-96. 
Bosman, H L, Hofmeyr, J W, Scheffler, E H, Van Eden, I J, Van Niekerk, E 1987. Die Nederlandse Geloofsbelydenis - Ontstaan, Skrifgebruik en Gebruik. Pretoria: Unisa (Studia Composita 1).

Carroll, R P 1991. Wolf in the Sheepfold: The Bible as a problem for Christianity. London: SPCK.

Charlesworth, J H 1998. The Dead Sea Scrolls and Christian Faith. In: Charlesworth, J H \& Weaver, W P (ed), The Dead Sea Scrolls and the Christian Faith: In Celebration of the Jubilee Year of the Discovery of Qumran Cave I 58-73. Harrisburg: Trinity (Faith and Scholarship Colloquies).

Charlesworth, J H \& Weaver, W P (ed), The Dead Sea Scrolls and the Christian Faith: In Celebration of the Jubilee Year of the Discovery of Qumran Cave I, 58-73. Harrisburg: Trinity (Faith and Scholarship Colloquies).

Deist, F E 1982. Sê God so? Protes en pleidooi - oor óns tyd, vir óns land. Kaapstad: Tafelberg.

-, 1986. Kan ons die Bybel dan nog glo? Onderweg na 'n Gereformeerde Skrifbeskouing. Pretoria: J L van Schaik.

Den Heyer, C J 1988. De oude bijbel in een moderne wereld. Kampen: Kok.

Doubell, B \& Strauss, S 2001. Woord van God of woord oor God? Op soek na 'n eietydse Skrifmodel. NGTT 42:302-314.

Du Plessis, P J \& Lategan, B C 1983. Agtergrond en geskiedenis van die Nuwe Testament. Pretoria: Academica.

Fokkelman, J P 1999. Reading biblical narrative: A practical guide. Leiden: Deo (Tools for Biblical Studies 1).

Hartvelt, G P 1968. Schrifkritiek en Schriftgezag in de 17de en 18de eeuw. In: Berkouwer \& Van der Woude 1968:15-37.

Heyns, J A 1973. Brug tussen God en mens: Oor die Bybel. Pretoria: NGKB.

Janse van Rensburg, J 2000. The paradigm shift: An introduction to postmodern thought and its implications for theology. Pretoria: J L van Schaik.

Jonker, W D 1975. Die Bybel en Gods wil vir ons lewe. Kaapstad: N G Kerk-uitgewers.

Koekemoer, J H 1994. Dogmatiek in die rigting van die Gereformeerde Ortodoksie? Skrif en Kerk 15: 87-94.

König, A 2001. Die helfte is my nooit oor Jesus vertel nie: 'n Nuwe kyk op die Een wat jou lewe verander. Wellington: Lux Verbi.BM.

Kushner, H S 1982. When bad things happen to good people. London: Pan books.

Moyise, S 1998. Introduction to Biblical Studies. London: Cassell (Cassell Biblical Studies Series).

Oosterhoff, B J 1968. Schriftkritiek en Schriftgezag in de 19de en 20e eeuw (O T). In: Berkouwer \& Van der Woude 1968:38-51.

Ord, D R \& Coote, R B 1994. Is the Bible true? Understanding the Bible today. New York: Orbis.

Potgieter, P C 1990. Skrif, dogma \& verkondiging. Kaapstad: Lux Verbi.

Scheffler, E H 1987. Die gebruik van die Nuwe Testament in die Nederlandse Geloofsbelydenis. In: Bosman, H L et al 1987:70-88.

Schnelle, U 1998. History and Theology of the New Testament Writings. London: SCM.

Skrifgesag en Skrifgebruik. Beleidstuk van die Ned Geref Kerk, soos goedgekeur deur die Algemene Sinode, 1986. 
Spangenberg, I J J 1994. Paradigmaveranderinge in die Bybelwetenskappe: 'n Bydrae tot die gesprek tussen die Bybelwetenskappe en Sistematiese Teologie. Teologie \& Religie 1:144-184.

-, 1998. Perspektiewe op die Bybel: God se Woord in mensetaal. Pretoria: J L van Schaik.

Swart, J J 2000. Die Bybel bly steeds God se Woord. Pretoria: Bienedell.

Van Huyssteen, W 1987. The Realism of the Text: A perspective on biblical authority (Miscellanea Congregalia 28), Pretoria: Unisa.

Verster, P 1997. Wie het die waarheid beet? 'n Vergelykende oorsig van die Christendom en die groot godsdienste van die wêreld. Vereeniging: CUM.

Viljoen, A C Ekumene onder die Suiderkruis (Miscellanea 19), Pretoria: Unisa 182208.

Vorster, W S 1977. 'n Ou Boek in 'n nuwe wêreld: Gedagtes rondom die interpretasie van die Nuwe Testament (Miscellanea 10), Pretoria: Unisa

-, 1979. In gesprek met die Landmankommissie: Oor Skrifgebruik. In Viljoen, A C (red), Ekumene onder die Suiderkruis (Miscellanea 19), 182-208. Pretoria: Unisa 